\title{
Methods and Tools Supporting Urban Resilience Planning: Experiences from Cork, Ireland
}

\author{
K. M. de Bruijn'1, H. van der Most ${ }^{1}$, L. Cumiskey ${ }^{2}$, M. Hounjet ${ }^{1}$, M. Mens ${ }^{1}$ \\ ${ }^{1}$ Deltares, Delft, The Netherlands \\ ${ }^{2}$ Flood Hazard Research Centre, Middlesex University, London, UK \\ Email: Karin.debruijn@deltares.nl
}

How to cite this paper: de Bruijn, K.M., van der Most, H., Cumiskey, L., Hounjet, M. and Mens, M. (2018) Methods and Tools Supporting Urban Resilience Planning: Experiences from Cork, Ireland. Journal of Geoscience and Environment Protection, 6, 290-309.

https://doi.org/10.4236/gep.2018.64018

Received: March 1, 2018

Accepted: April 13, 2018

Published: April 16, 2018

Copyright $\odot 2018$ by authors and Scientific Research Publishing Inc. This work is licensed under the Creative Commons Attribution International License (CC BY 4.0).

http://creativecommons.org/licenses/by/4.0/

\begin{abstract}
To prevent flood disasters, policymakers call for resilient cities which are better able to cope with flood hazards. However, actual adoption of resilience measures in urban planning is still limited, partly because it is not sufficiently clear how and to what extent resilience should and can be enhanced. To develop resilience strategies, information on the current resilience and on the effects of measures should be available. Since cities are complex systems, an assessment of resilience requires the input of different actors. To obtain and combine this input, a comprehensive approach which brings together many actors is required. Furthermore, resilience must be integrated in planning frameworks in order to enhance adoption by city policy makers. Tools which support and structure the contribution of different disciplines and actors will help to obtain information on the current resilience and to develop a shared vision on measures to enhance urban resilience. We illustrate our view with an example on Cork, Ireland.
\end{abstract}

\section{Keywords}

Urban Resilience, Flood Hazard Mitigation, Flood Risk Management, Urban Flood Management, Multi-Actor

\section{Introduction}

The world's policymakers, authorities, development organizations and donors emphasize the need for more resilient cities [1] in order to prevent hazards from resulting in disasters. The Sendai Framework for Disaster Risk Reduction 2015-2030 calls for more attention for resilience [2], as do the New Urban Agenda [3] and 
the Sustainable Development Goals [4]. Resilience also constitutes the paradigm of the 100 Resilient Cities campaign by the Rockfeller foundation [5]. These global policies, however, do not provide practical guidance for assessing and enhancing flood resilience within urban systems.

There is an on-going debate within the scientific community on the description and definition of resilience [6] [7] [8] [9]. Although the precise definition of resilience may not be agreed upon, there is nevertheless agreement on the notion of resilience and the most important system characteristics to enhance cities' or deltas' resilience to be better able to cope with hazards, such as extreme weather events and floods [10]. Recently, attempts have been made to derive principles based on those shared insights which may help policy makers define measures that enhance resilience. [11] proposed ten "essentials" for making cities resilient including conducting risk assessments, ensuring stakeholder participation, protecting critical infrastructure (abbreviated further as "CI") and assigning budgets. [12] developed a city resilience index. [13] provided guidance on how to build urban resilience to natural hazards. They claim that cities should protect their citizens and that public funding of resilience is therefore justified. They promote the sharing of risk information with actors to increase resilience and mention a number of critical steps such as: taking into account future uncertainties, looking at various aspects of the disaster chain and focusing on critical infrastructure. [14] defined lessons learned from hurricane Sandy and also mentioned sharing of information, anticipating on uncertain futures and aligning various policies and programs. [10] proposed five resilience principles for policy makers and consultants to guide enhancing resilience to natural hazards.

Although such principles and essentials help to make resilience more concrete, resilience needs to be included in commonly used policy frameworks to promote implementation of resilience measures. Information on current levels of resilience must be made available to enable informed decisions on the usefulness of resilience enhancing measures. Cities are highly complex and dynamic systems; their current and future resilience to a certain hazard will depend on many actors, processes and measures. Hence it is very difficult to quantify resilience and to assess the effect of measures on resilience, especially by local authorities themselves. Therefore, we propose to adopt approaches and tools which enable input of a wide range of actors from different fields, structure their discussion and contribute to the development of a shared vision on the cities' resilience and ways to enhance it.

This paper clarifies what we mean by resilience and then links resilience to policy frameworks to identify what information is needed to support policy makers in their search for resilience enhancing measures. Next we discuss the type of approaches and tools which may help obtain such information and illustrate this by an example of planning of urban resilience against floods in Cork, Ireland. We explain that resilience planning benefits from methods and tools which support the structuring and integration of information of different discip- 
lines and actors to get a comprehensive overview of urban resilience.

\section{Theory: Urban Resilience to Floods}

Resilience as a concept covers significant elements missing in "traditional" management of flood risks. Traditionally, flood risk management approaches focus on risks which are understood as a combination of flood probabilities and flood consequences [15]. Flood risk is often expressed in terms of the expected annual damage or expected annual number of casualties [15] [16]. Policy makers evaluate these risks by comparing these with acceptable risk levels or in an economic assessment. Reducing risks requires taking measures that reduce either the probability of an event happening or its consequences. An economic cost-benefit analysis will provide insight into the efficiency of proposed measures.

Such commonly applied risk analyses have some drawbacks: they neglect risk aversion in society and pay little attention to rare, but catastrophic events [17] [18]. These analyses often focus on direct tangible impacts and do not consider recovery, indirect effects and intangible impacts [18] [19]. Additional criteria are thus needed to assess measures.

The call for enhancing resilience usually includes a call for more attention to rare, but catastrophic beyond-design events, to intangible impacts, indirect effects and to recovery capacity of the society threatened by disturbances.

Resilience is generally considered a positive system characteristic that is related to the system's ability to cope with disturbances [20]. In policy documents resilience is generally defined at a large scale and not hazard specific. It needs, however, to be specified and operationalized in order to address it [21] [22] [23]. Both the system and the relevant disturbance should be clearly specified in order to define, implement and monitor resilience measures: "resilience of what to what?" [24].

In this paper, we define urban flood resilience as the ability of a city to cope with high rainfall intensities, river water levels and coastal storm surges either by being able to withstand those disturbances, or by recovering easily from the impacts they cause.

In evaluating resilience strategies, we consider how the set of measures building the strategy perform under different future scenarios of the urban area. To assess resilience, first the system boundaries and specific flood hazard must be defined and then relevant indicators to measure flood impacts and flood recovery time must be selected.

To support policymakers to deal with flood resilience, [10] translated the notions related to resilience into five guiding principles, namely:

1) Adopt a system's approach: To tailor flood risk management strategies to the socio-economic system, a comprehensive systems understanding is needed, including the interdependencies between subareas and the link between flood risks, recovery, economic activities and social networks [25];

2) Look at beyond-design events: The risk perception of events with a low 
probability but high consequences is often different from the "objective" risk as provided by economic analysis [17]. Rare but catastrophic events may call for measures which are not cost-effective in view of a standard cost-benefit analysis;

3) Develop infrastructure according to "remain functioning" principle: Design systems in such a way that consequences of failure are not catastrophic, but manageable;

4) Increase recovery capacity by looking at social and financial capital [26]. Measures which increase people's ability to recover include amongst others measures aiming at improving education level and well-fare but also measures which improve access to recovery funds e.g. insurances, relief grants, reconstruction employment schemes and so on;

5) Consider future changes in order to remain resilient into the future: Systems' resilience changes due to climate change, urbanisation, economic changes and economic growth. To remain resilient in the future, urban areas and urban policies need to be flexible, and urban planners need to learn and adapt to cope with gradual but uncertain changes.

These principles help policy makers to adopt a resilience approach, but they need to be translated to urban planning and tools and methods to support adoption will help further uptake.

\subsection{Flood Resilience in Relation to Urban Planning}

Cities are complex systems with many interrelations. The functioning of urban areas and the well-being of people in flood-prone cities may be threatened by floods. However, flood threats are just one of the many challenges which urban areas need to cope with. Others are for example urbanization, aging infrastructure, access to (sustainable) energy and social issues. To increase urban flood resilience, the other developments and challenges need to be considered, and strategies need to be understood in view of changes. As an example we mention the city Chennai in India where severe floods occurred in 2015. When addressing these floods, it is crucial to also address other major issues such as the aging and insufficient capacity of sewer and garbage management systems and to take into account the very high grow rate of the city [27].

Increasing resilience and developing sustainable pathways into the future, requires interaction between actors, and authorities and integration of knowledge on flood risks with information on urban activities, developments and assets [28]. Through mutual learning a shared vision can be developed on current levels of flood resilience and on potentially feasible measures to maintain and enhance resilience in the future.

Common policy frameworks for urban planning follow steps such as problem exploration, risk analysis, risk evaluation, and defining strategies [29]. We propose an urban resilience planning framework, which reflects the policy cycle (see Figure 1). It consists of four steps that are to be followed in an iterative way. Reaching agreement on problem assessment and policy objectives is the key to 


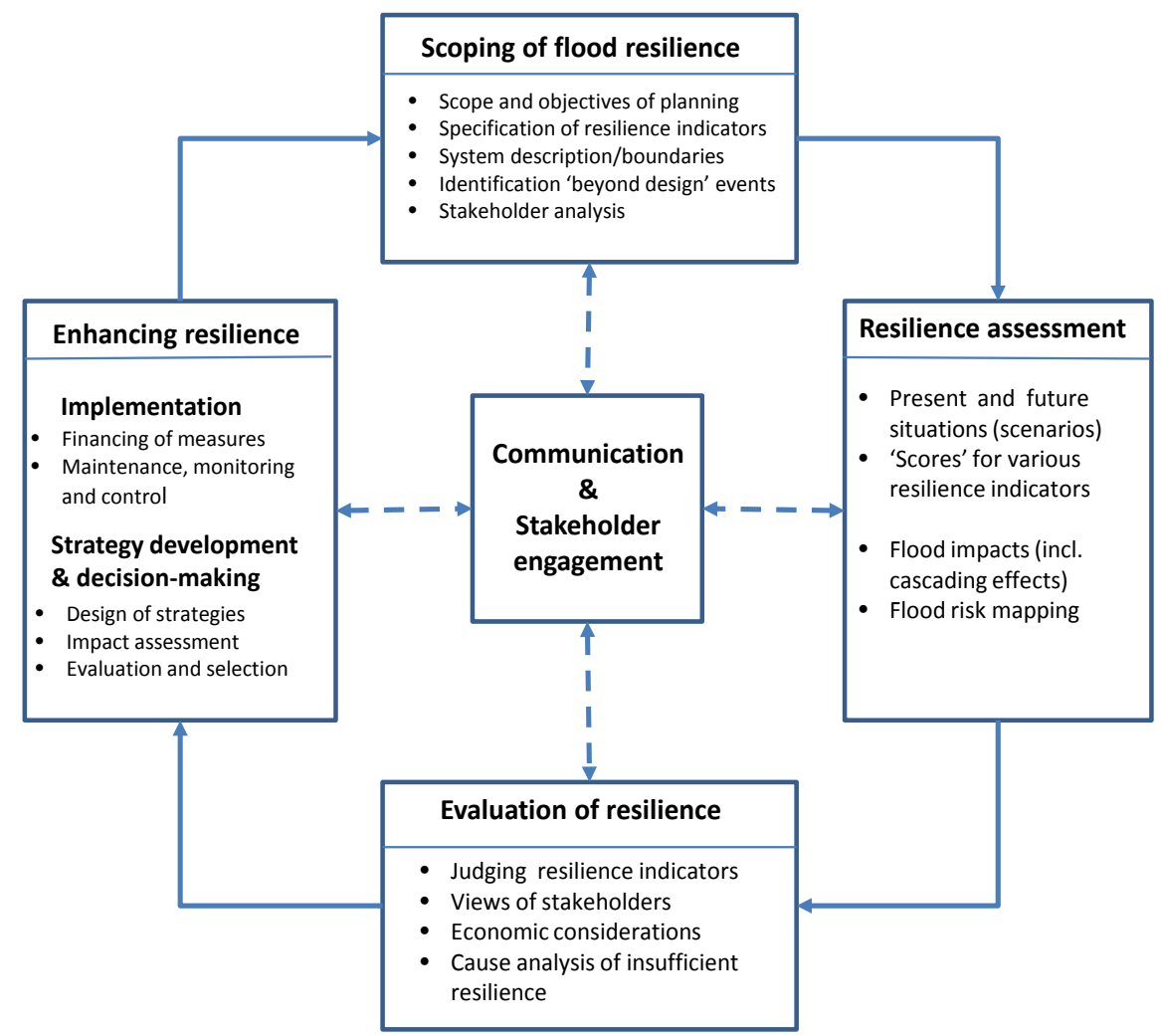

Figure 1. Framework for policy analysis and planning of urban flood resilience.

successful planning. Hence stakeholder engagement and communication are at the core of the framework: a process of joint fact finding to understand perceptions and develop a common knowledge base.

\subsection{Scoping of Urban Flood Resilience}

Resilience planning processes start with an inception phase in which scope and objectives of the planning process are defined: the hazards addressed and objectives pursued. Starting-points for the next steps are defined in the planning cycle. This includes specifying the dimensions of resilience together with related indicators. Choices have to be made to describe the system and its boundaries: what aspects and relationships are considered in the analysis of urban flood resilience.

Scenarios (i.e. plausible future situations) need to be defined that account for various uncertainties, including the possible impacts of climate change. Scenarios play a central role in defining adaptive strategies and help to define and prioritize low regret measures. Furthermore, "beyond design events" need to be identified to enable the assessment of flood resilience. Relevant actors need to be identified through an actor analysis.

\subsection{Resilience Assessment}

The level of resilience will be analyzed by calculating various indicators reflect- 
ing flood resilience for both the current situation and future scenarios. Particular attention should be paid to "beyond-design events". The analysis looks into different types of flood impacts, including cascading effects on CI, i.e. effects of disruption of $\mathrm{CI}$ in flooded areas on $\mathrm{CI}$, industries or communities outside the flooded areas. Through a flood risk mapping exercise a comprehensive overview can be compiled of hazards, impacts and risks in the project area, which serves as input to the evaluation and management of flood resilience. Some of the resilience indicators may be quantified using computer simulation models; for other indicators a qualitative assessment may suffice.

\subsection{Evaluation of Resilience}

The next step after establishing the degree of resilience of the current system is the resilience evaluation. Evaluating resilience is essentially a societal and policy process which should answer the question: "How resilient is resilient enough?" Such evaluation will help to decide what measures and strategies are proportionate to the perceived lack of resilience. The inputs to this discussion are flood risk maps, the values of indicators for different scenarios, the potential measures to reduce risk and enhance resilience and their associated costs. It includes stakeholder views as well as economic considerations regarding the acceptability of side effects and damages, and the cost-effectiveness of measures enhancing resilience. The evaluation of existing resilience should also clearly identify the main causes of insufficient resilience. Such insights will provide guidance to the development and selection of measures and strategies that enhance resilience.

\subsection{Enhancing Resilience}

Strategies to enhance resilience should include a well-balanced mix of structural and non-structural measures, including measures which can be implemented in the short term. The strategies will be assessed on economic feasibility, social and cultural aspects, and environmental considerations under a wide range of future scenarios. The development of strategies in an interactive setting may be supported with decision support systems. Implementation of strategies will look into the financing of measures, as well as on-going long-term operation and maintenance costs. Governance arrangements should create the conditions for effective enforcement of regulations and public awareness campaigns.

\section{Methods and Tools Which May Support Planning for Resilience}

\subsection{Type of Tools and Methods Needed}

In order to identify, analyze and evaluate measures which enhance resilience of cities we need methods and tools which produce information on system behavior, on the impacts and recovery rates of disturbances and on the effects of potential measures. Such an overview is not easily obtained as it requires information from multiple actors and disciplines. The literature suggests that approaches 
which engage actors and stimulate joint fact-finding can offer guidance in developing resilience strategies [30]. In order to engage actors and obtain an overview of the whole urban system in relation to flood risks, interviews and workshops with experts and actors are needed. Such workshops may also enhance capabilities of actors and create ownership of resilience objectives, approaches and the way forward. They can help actors to relate their knowledge and responsibilities to the functioning of the system as a whole. They may also contribute to a shared vision on what measures or strategies are best and what actions should be taken by the individual actors. Methods and tools that structure and enhance discussions during workshops are crucial to reach this common view. Such workshops are beneficial for all four phases in the proposed urban resilience planning framework.

There is a wide variety of methods with different levels of participation available to engage actors [31]. Different methods include focus groups [32] and the Delphi method [33]. Two recently developed methods/tools, the CIrcle Tool and the Storyline Method, aim to better engage actors in the planning process. The storyline method helps to sketch the chain of events and actions, before, during and after a flooding which shows links between actions and actors [34], while the CIrcle tool structures and visualizes information on CI vulnerability [35]. Both aim to contribute to the development of a shared vision on the current levels of resilience and on potential measures to increase flood resilience of the city as a whole. The methods use existing information on flood risks, and involve many different disciplines and actors. This section discusses these methods and the case study on Cork will illustrate how they help to assess the current resilience and the impacts of potential resilience measures.

\subsection{Storyline Method}

The storyline method comprises selecting and analyzing specific scenarios together with relevant actors to identify the sequence of events, the responses of actors and the interactions between the actors. The storyline considers the sub events just before, during and just after the flooding. This approach does not replace, but complements common risk analyses. The way in which actors relate flood risk maps (which often contain aggregated information from many potential flood events) to their own actions and designs is not always clear. A storyline which corresponds to an extreme but realistic event, helps communication and clearly delineates actions between actors. The storyline method is thus principally designed to facilitate communication, information exchange and discussions in workshops. It has been applied in the Netherlands, to develop and analyze flood risk management strategies for the Island of Dordrecht [34].

The storyline approach comprises four steps which match with the resilience framework. In the scoping phase of the resilience framework, the first two steps are considered:

1) Initial phase: Describe the area, the flood hazards, the CI and relevant ac- 
tors;

2) Select the scenario for the storyline: A scenario consists of an extreme weather event and/or other cause of flooding;

In the resilience assessment phase the third and fourth step are executed:

3) Develop the storyline and describe how the event evolves before, during and after the flooding;

4) Analyze the flood impacts such as damage, fatalities, number of persons impacted and recovery duration.

In the resilience evaluation and enhancement phases the outcomes are discussed, potential measures selected and the storyline is reconsidered for a future situation in which the selected potential measures are assumed to be implemented.

The storyline describes for each of the three flood phases: (1) the rising of the flood threat, (2) the flooding itself, and (3) the recovery from the flooding, the following aspects: the flood pattern, the effects on CI, as well as the actions of the most relevant actors. Actors include local authorities, meteorological services, water managers, emergency responders, CI operators and the general public. The interrelations between actions and actors can be visualized in tables or diagrams.

The storylines should not be considered as forecasts with a certain probability, but as "what if" scenarios. They will provide a consistent set of assumptions, reveal uncertainties and provide a picture of the interactions of actors.

It is recommended that researchers first prepare and develop storylines based on available information from literature or interviews of key-actors and then repeat the storyline development in a workshop together with representatives of the key-actors to complete and correct the storyline and exchange knowledge.

The application of the storyline approach in workshops brings together actors from diverse disciplines and institutes, such as flood modelers, crisis managers, emergency services, spatial planners, and critical infrastructure managers. The approach is applicable also when data is not available. It results in a shared view on what may happen and on how different responses or situations interact. It also reveals data needs and contributes to strategy and measure identification [34].

\subsection{CIrcle}

Since one of the conditions for a resilient city is having resilient CI, we also discuss the CIrcle approach and tool as an example which supports urban planners in their resilience planning process. This tool is used to engage actors from different $\mathrm{CI}$ networks to understand and analyze the cascading effects of floods on their CI networks [35] [36]. It supports the development of a mutual understanding in workshop sessions and it visualizes actors' input on different CIs and the interrelations between those CIs.

The CIrcle workflow consists of several steps. First, the actors are asked to de- 
pict CI on a map of the flood-prone area. Since obtaining high quality data on CI may be difficult due to security and competition, the actors are not requested to bring in detailed data sets, but instead they are asked to locate CI on a map in a confidential workshop setting. Such maps and the corresponding explanation of the actors are often sufficient to get an overview of the vulnerability of the CI to flooding and the interactions between different CI networks.

Secondly, all identified CI networks are presented as blocks in a circle diagram on the CIrcle tool (see Figure 2) and for each CI network the resistance and resilience to flooding is discussed. The network components' resistance is the water depth which the element can withstand without any damage and its resilience is related to the damage severity and recovery rate. If, for example, a power supply operator brings forward that failure in power supply will occur if water depths exceed $25 \mathrm{~cm}$ at the network control cabinets, then in the outer circle of the diagram one block is assigned to power supply and the threshold of $25 \mathrm{~cm}$ is then added.

Thirdly, for each vulnerable CI network type it is discussed if failure in service could trigger other CI networks to fail. If a failure in the power supply occurs, will, for example, the emergency managers be able to continue their work and if so, for how many hours? This information is then added as causal links between the blocks in the outer circle (see Figure 2). Generally, more information on the links is obtained from the group discussions than from discussions with individual actors. Finally, the effect of the disruption of CI on society is addressed and added to the CIrcle tool (number of people affected, costs, etc.).

\section{Illustrative Example: Urban Flood Resilience of CI in Cork, Ireland}

We illustrate the urban resilience planning framework and the methods and tools through their application in Cork. In the case study, we started with scoping the resilience issue: delineated the system and specified the hazard towards which resilience is needed. Then we did an actor analysis and proposed case specific resilience indicators. Then we assessed the resilience, evaluated it and considered measures to enhance the system's resilience.

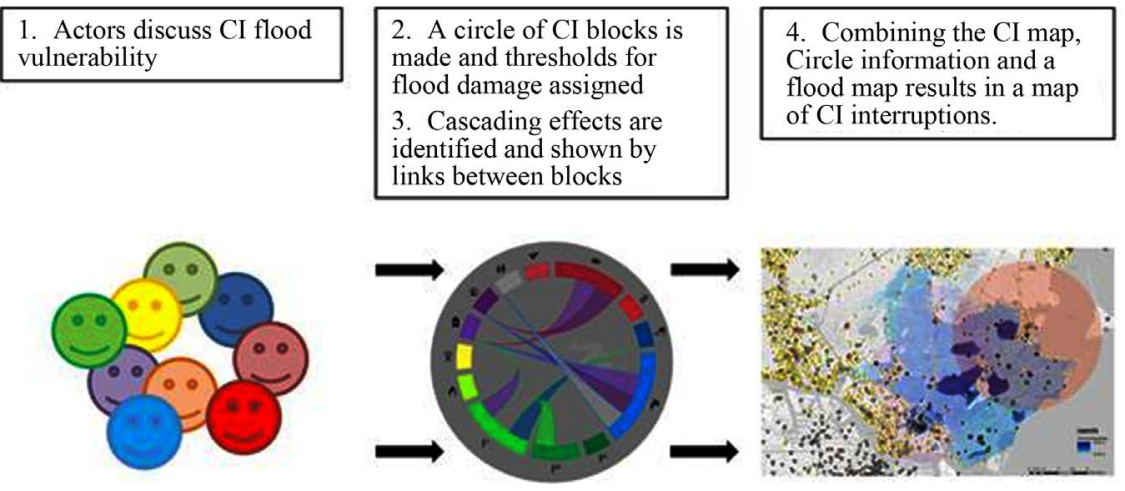

Figure 2. Flow diagram of the CIrcle tool and approach (based on: [37]). 
To understand the system, literature was studied and actors were interviewed. The most important actors in the Cork case are the CI operators, local authorities and emergency managers and experts from the Office of Public Works (OPW). First unstructured interviews and interviews based on a strict questionnaire were held. The unstructured interviews served to exchange information on the project scope, needs and challenges of the stakeholder and context. The questionnaire based ones focused on obtaining specific information on CI vulnerability of Cork County. Based on the obtained information from experts and actors, from literature on flood events, protocols for emergency management and plans for future measures, it was decided to focus on one specific clearly defined flood scenario and adopt the storyline approach and CIRCLE tool for further analysis.

In the assessment phase the selected storyline was prepared. Then a workshop was held on the 9th of March 2016 with representatives of the City and County Council, and CI operators and managers to jointly elaborate the storyline. The CIrcle tool was used to support the workshop and to collect, visualize and present the information in a structured and coherent manner. After the workshop, the outcomes were combined into a description, graphs and maps.

In the evaluation phase a second workshop was held in which the outcomes of the first workshop were shared and discussed (September 2016). This workshop also focused on identifying further measures and thus also covered the enhancing resilience phase. The questionnaires, interviews, workshop report and case study report were kept confidential to promote engagement between actors.

To assess flood resilience of Cork City Centre we used two indicators, one for impacts: the monetary impacts related to a once in 1000 years flood and one for recovery: the number of affected person days which is equal to the product of the number of persons affected and the duration they are affected. We focused on the once in 1000 year scenario, which is a beyond-design event. The resilience indicators and findings are discussed in the next sections.

\subsection{Scoping Phase}

Cork City is the largest urban settlement within the Southwest Region of Ireland. Cork City was originally built at the mouth of the River Lee, on an island in a marsh and is thus susceptible to flooding. The flows in the River Lee are influenced by two hydro-electric dams owned by Electricity Supply Board (ESB). Cork City is at risk of tidal flooding during extremely high tides, by flooding from river discharges, and combined tidal and pluvial flooding. Fluvial floods are most damaging. The city has 120,000 inhabitants, comprises a large concentration of commercial and industrial activities, nationally important $\mathrm{CI}$, and attracts a large commuter population from the surrounding hinterlands.

Flood management is carried out by the OPW at national level, the County and City Councils at regional and local level. Since the ESB manages the reservoirs which may attenuate flood waves, they influence flood risks significantly. 
The CI in Cork includes transport networks, utility services and furthermore there are vulnerable and crucial assets such as emergency services, hospitals and the university. In the management and operation of CI several actors are involved, including CI operators and managers (road, rail, air, port, water, energy), local authorities and first responders. A full description can be found in [38].

In 2009 a severe river flooding occurred which resulted in severe damage and interruption of critical infrastructure services: The main transportation routes were cut off, the roads to and from the hospital became inaccessible, the drinking water supply of about 87,000 persons was interrupted for about two weeks and the university suffered from large damage.

Since the flood event of 2009 damaged the CI severely, the study on the flood resilience of Cork focused on CI. We focus in this paper on the resilience of Cork City CI to fluvial flooding.

\subsection{The Resilience Assessment Phase: The Storyline-CIrcle Approach}

\subsubsection{The CIrcle Diagram}

To assess flood resilience, a workshop was organized in March 2016 and attendants of the City and County Council, CI operators and managers and emergency managers were present. First the flood scenario was discussed and then the actors added $\mathrm{CI}$ locations to the $\mathrm{CI}$ maps and identified the $\mathrm{CI}$ present in the region. Based on their inputs the original CI map was improved. For each CI type the potential direct flood impacts and the thresholds for those impacts were discussed. For the medium voltage transformer stations, for example, the threshold for flooding and failure before 2009 was about the flood depth of 2009 . However, recently they have been protected from flooding and now they can resist water depths of $1 \mathrm{~m}$ above ground level. Potential cascading effects arising from the flooding scenario were also identified during the process, allowing for a more comprehensive determination of impacts. For example, the effects of disruptions in power supply on the functioning of the hospital were discussed. The cascading effects were imported directly in CIrcle as links between the blocks which represent the CI types (see Figure 3).

Most indirect effects are associated with the disruption of the transformer stations. The disruption of power affects schools, traffic systems, waste water treatment plants, local residents and the commercial sector. The disruption of the electricity network also had a cascading effect on the local hospital which was forced to run on its emergency generator.

The disruption of water supply also results in many cascading effects, e.g. to the schools, hospital and emergency services (fire services for example). Flooding of the road network has cascading impacts on the functioning of the local hospital; access to the hospital by emergency services and staff was compromised due to inaccessible roads. The flooding of roads also hampered emergency services. 


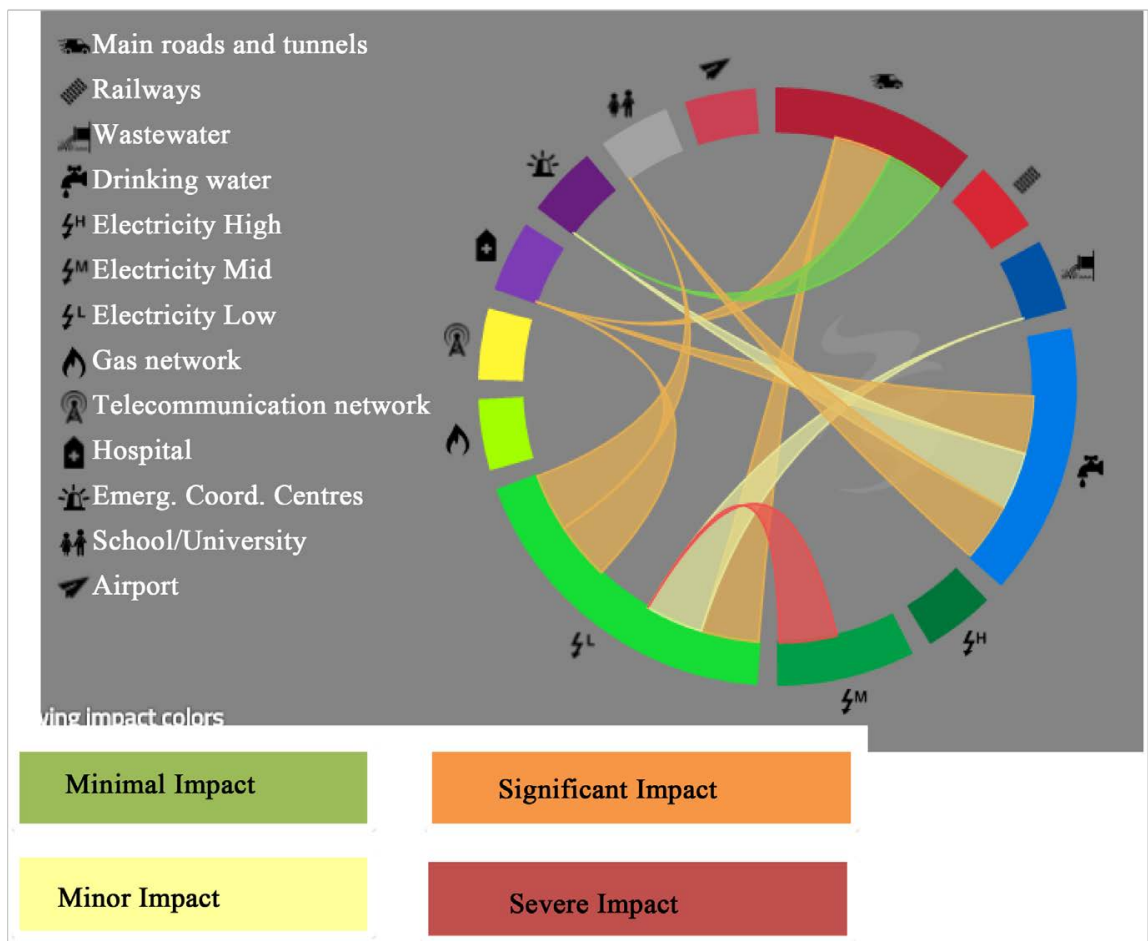

Figure 3. Result of actor discussion on cascading effects (based on [37]).

\subsubsection{The Resulting Storyline}

Based on the knowledge from the scoping phase we selected a once in 1000-year river flooding for the storyline. This is a beyond-design event which is a little more extreme than the 2009 flooding which was estimated as between a 100 and 1000 year return period. The three storyline phases (before, during and after the flooding) are briefly described below. A full description is found in [37].

\section{Phase 1: The escalating threat of river flooding}

Following a particularly wet October, soils are saturated and reservoir levels are very high. The ESB is releasing already $150 \mathrm{~m}^{3} / \mathrm{s}$ which causes local flooding. As prescribed in protocols, the ESB communicated this information to a pre-determined list of actors including Cork City and County Councils, University College Cork and shoreline property owners. The rainfall levels are continuously monitored and catchment assessments are continuously made to inform on the threat of flooding.

Then Met Éireann (the meteorological service of Ireland) informs that additional significant rainfall is forecasted over the coming 24 hours. They issue a level orange weather warning for the Southwest Region. The ESB foresees they need to increase discharges from the dam far beyond the maximum of $150 \mathrm{~m}^{3} / \mathrm{s}$ and they now indicate to the list of actors that they will need to release more than $400 \mathrm{~m}^{3} / \mathrm{s}$ from the reservoir to protect the integrity of the dam. They are aware this will cause significant flooding downstream.

The Flood Assessment Team and Flood Response Group are notified of the continued increase in discharge of water from the dam and are aware of the risk 
of flooding to the city centre. Cork City Council initiates the city's emergency management plan. They decide to restrict traffic movements in projected high flood risk areas and consequently close off vulnerable roads, city centre car parks and divert traffic at key junctions, although flooding has not yet occurred.

\section{Phase 2: The flood event itself}

At $\mathrm{t}=0$, river water levels are rising fast in areas which are normally dry, and some river bank and quays break, resulting in flooding of areas of the city centre (see Figure 4). The flooding is unexpectedly severe. The maximum water level is reached after 12 hours.

Cork City Council and emergency responders immediately respond to the breach by closing off the affected road and start repair works on the quay wall in order to prevent further flooding. The Crisis Management Team is coordinating the emergency response team and decides on further actions needed to close of roads and public areas, to prepare to transport people out of the flooded area, to monitor the situation and to assist affected inhabitants. Once the event has been declared a "Major Emergency", the National Coordination Centre is established. The key CI owners are represented in this body also.

$\mathrm{CI}$ is now affected seriously. In this hypothetical scenario the roads along and across the river have become flooded and thus inaccessible. These include national primary roads. Cork City Council closes part of these roads and diverts traffic away from the city centre. There is a cessation of bus services and also the movement of emergency services is significantly restricted as the flooding of city centre roads increases. Small boats are deployed in some areas of the city to rescue trapped residents from their homes and to transport medical personnel to work in the city centre hospital.

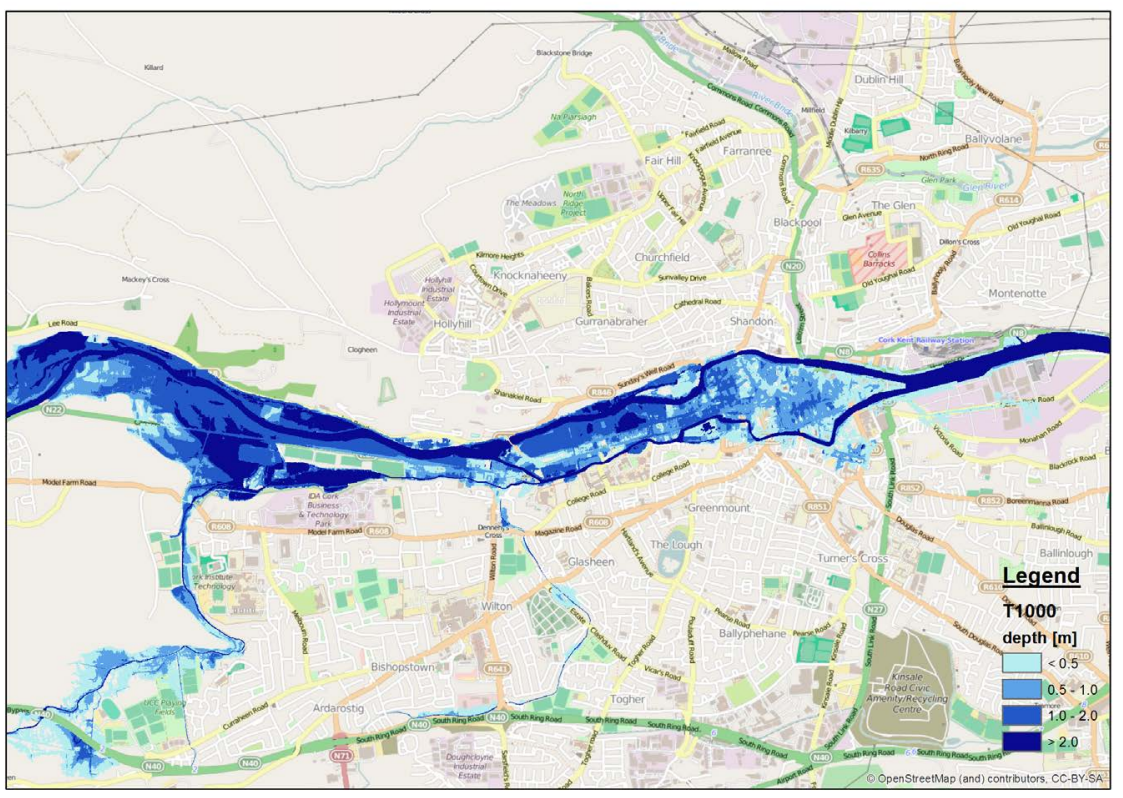

Figure 4. Flood map of the 1/1000 year flooding near Cork (based on [39]). 
Two transformer stations which were almost flooded in the 2009 flooding and deliver power to over 20,000 persons become flooded in this hypothetical event and cause a power shut-down in a large part of the city. This affects schools, traffic systems, and commercial areas: the whole society of the central part of the city. The railway network, the gas supply and communication networks are affected indirectly due to the large power disruption caused by the flooding of the two transformer stations.

The drinking water treatment facility is submerged which causes an interruption in drinking water supply also in areas of the cities which have not been flooded. Hospitals are provided with water to ensure continued operation. The water supply to fire hydrants is also impacted.

Flood waters enter the Mercy University Hospital but can be stopped before it reaches the generators which are located on the ground floor. The hospital becomes inaccessible. Hospital staff and crucial supplies need to be brought to the hospital by emergency responders.

The buildings of the University College Cork and the Tyndall National Institute are both flooded and consequently closed. The auditorium faces a flood depth of about $5 \mathrm{~m}$. Students are rapidly evacuated and temporary accommodation is arranged for them. No fatalities occur.

The citizens of Cork respond by protecting their homes and belongings and some are evacuated. Some residents installed personal door flood barriers in advance of the flooding which proved to be very effective. The general public are not only affected directly by the flood water, but also by the disruptions in CI functions.

\section{Phase 3: Post-flood event recovery}

The flood waters recede after approximately 24 hours. Most roads and bridges are accessible again by then, but power supply and water supply remain interrupted for a period of up to two weeks.

Since approximately 25,000 properties are without drinking water supply, Cork City Council brings in large mobile tankers to distribute fresh water to the areas without potable water supply.

Quickly, businesses, public services and educational re-open and university classes recommence. However, some areas of the university campus are closed for up to nine months while repair works are completed. Approximately 10,000 students and 30 staff are relocated. Temporary lecture rooms and student accommodation are obtained in the interim period to ensure that classes can proceed.

\section{Storylines for current situation (2017) and the future}

If a flooding event similar to a $1 / 1,000$ event would occur in 2017 , consequences would differ from those described previously (related to a pre-2009 flood event situation). Since 2009 important measures have been taken:

The preparedness for extreme conditions has improved significantly: the functioning of the action teams and emergency coordination has changed and 
emergency protocols and procedures have improved;

$\square$ The management of the reservoirs and the information supply to the reservoir operators has been significantly improved.

$\square$ The electricity transformer stations have been protected against water depth of approximately $1 \mathrm{~m}$;

$\square$ Structural faults in the quay walls have been repaired and the walls strengthened which reduces the inundation depths due to such extreme events;

$\square$ Flood defense measures have been implemented at the university; and

$\square$ Improved flood defense measures have been incorporated at the drinking water plant to increase protection of the infrastructure.

The event storyline would start similarly to that of the pre-2009 scenario, but in the flooding phase, impacts would be limited to the roads along the river. The drinking water plant is still vulnerable to this type of flood scenarios. However, it is believed that emergency managers now can prevent flooding by effective emergency actions. Flood defense measures implemented to the power supply, water supply and the university increases resilience to flood events. Furthermore, the structural improvement works to the quay walls are likely to reduce the risk of flooding to the Mercy Hospital. Another important element is the preparedness of the general public to flooding: the experience of a recent large scale flood event would also act to improve preparedness and encourage residents and businesses to increase their level of flood defense. Therefore, it is expected that floods would still cause impacts at the areas directly along the river, but that after about 3 days, the area would have recovered.

In future additional measures are planned by the OPW: hydraulic models will be made to further enhance the capacity of the reservoir operators and Cork City Council to forecast water levels and to operate the reservoir. Flood storage areas will be planned between the reservoirs and Cork City to prevent flooding of vulnerable urban areas. These actions increase resilience. The final resilience level depends, however, also on the degree of climate change and urbanization and spatial planning of the City and County Councils.

\subsection{Evaluation Phase}

To evaluate whether Cork is sufficiently resilient, the acceptable resilience level must be assessed. In Ireland there is no formal safety standard, acceptable risk threshold, or other type of standard. However, it was clear that the flood impacts of the 2009 flood were found to be unacceptable. Therefore, measures were taken after 2009 to prevent such impacts from happening again. The potential flood impacts of events such as the 1/1000 year event in the storyline exceeded the 2009 event, and were thus also unacceptable. How much improvement is needed to reach an acceptable level of resilience was still open for discussion. The continuing interest in flood risk and flood impact studies, in resilience and CI vulnerability may be considered as an indication of the search to determine what is feasible to do to increase resilience and what levels are required. 
To be able to discuss resilience in urban planning, a rough indicative analysis is presented of the resilience before and after 2009. Almost all of the city's 120,000 residents were impacted directly or indirectly as a result of the flooding in the pre-2009 situation. Monetary impacts exceed the $€ 60$ million in flood damage costs which occurred in 2009 [39], and recovery lasts for up to nine months. Although there were no casualties, the flooding is considered disastrous. The city is considered very vulnerable and not resilient to flooding.

The direct impacts were significant, but the indirect impacts due to disruptions in power supply, drinking water and transport routes were much more severe, affected also non-flooded citizens and lasted much longer. To reduce impacts and increase recovery rate those indirect impacts need to be focused on. To assess the recovery rate in this case we simply multiply the number of affected persons by the duration of the impacts. In the storyline of the pre-2009 situation almost the whole population suffered for about 2 weeks due to cuts in power supply and interruption of services from busses, railroads, communication and so on. About 87,000 persons were also without drinking water in that period. Although students were still evacuated and some university buildings were still seriously damaged after those two weeks, the university functioned again and lectures were given. The recovery time indicator was assessed as 120,000 inhabitants ${ }^{\star} 14$ days $=1.68$ Million person days.

If a flood would occur in 2017, probably only the citizens close to the river, or those who depend on roads along the river are affected and they face little damage. The number of people exposed in 2017 is not known precisely. If about 300 persons would be affected during a period of 3 days, the recovery time would be 3 days ${ }^{\star} 300$ persons $=900$ person days, which is much less than before 2009. The estimated damage is also a fraction of the pre-2009 situation damage.

The measures which were already taken thus increased resilience significantly. They focused on flood prevention (strengthening of quays, protecting the university grounds), emergency management, and impact reduction by protecting the drinking water production and power supply assets, which caused the largest impacts in 2009. Even if beyond-design events occur and the city is flooded, the power supply is likely to remain intact, and the more efficient emergency management would limit impacts and enhance recovery. Resilience thus has increased very much thanks to the implemented measures.

\subsection{Further Enhancing Resilience Phase}

In future, resilience may be further enhanced if e.g. flood storage areas are assigned and emergency management is further improved. Future changes, such as urbanization in floodplains, or climate change may however also reduce future resilience. To make decisions on the need for further resilience enhancement regular (e.g. every 10 years) reconsiderations of flood risk and flood resilience are beneficial. Advanced resilience indicators which provide more information than the presented first attempt indicators may then be developed. The actors 
involved in the workshop would like to contribute to a shared vision for the cities' resilience towards floods and are very interested in all information on flood hazards, the foreseen responses of the emergency managers and on the impacts on networks linked to their own network.

\section{Discussion}

Global policy documents, scientific literature and practitioners' statements emphasize the need for enhancing urban resilience. Actual implementation of resilience measures in urban city planning will require a clear vision on how and to what extent resilience should be enhanced. To promote the adoption of measures enhancing resilience in urban city planning, resilience must become part of existing planning frameworks and information on the effect of measures on resilience must become part of assessment frameworks. Traditional flood risk analysis techniques are often insufficient to assess resilience, since they do not address recovery, intangible impacts, and pay little attention to impacts from beyond-design events. We showed that with approaches which engage a wide range of actors useful insights on resilience and resilience enhancing measures can be obtained.

In Cork the assessment focused on the effect of a beyond-design flood event on the functioning of CI. Such events, disrupting CI, were experienced in recent flood events of 2009. We applied the storyline approach to structure and focus discussions and used the CIrcle tool to collect, structure and visualize flood effects on CI including cascading effects. Joint fact-finding with actors promoted dialogue and increased awareness between actors who normally rarely interact. It helped them to better understand the linkages between the various systems and responsibilities, which also increases acceptability of both flood risks and measures. It also helped to determine locations or assets which need to be raised or protected with priority because those determine recovery rates or are crucial for emergency management. The approach followed allows all actors to provide information, exchange ideas and to obtain a shared vision of the issues and solutions. In the workshop the participants walked over to the map, identified their networks and saw which were in flooded areas. Then for each CI the effect of the water on the functioning was discussed. The area which would be affected and the effects on other CI networks were discussed next. Lively discussions emerged on potential flood effects, cascading effects, risks which are already being considered or not and on potential measures and who should take them. Seeing the complete picture clearly contributed to identifying measures which are beyond the scope of single actors.

Other approaches to obtain information on flood impacts, flood risks and vulnerability, such as traditional flood risk analysis methods which were carried out by technical engineers focused on direct impacts. Risk analyses of CI managers focused on the impacts for their own CI. Issues at their own CI caused by disruption in other CI networks were sometimes overlooked when studying 
flood hazards, or if identified, they were considered beyond their responsibility (as someone mentioned in a working session when discussing railroad vulnerability to coastal floods "those power suppliers should have their operations working"). The approach followed here which includes cascading effects and brings together different actors is not common yet.

However, the success of the approach will depend strongly on the active involvement of the right actors and an adequate support of the joint fact finding process, including a proper preparation of workshops. Since in Cork, the willingness to improve flood resilience is large and we discussed the workshops intention in interviews, we were able to get the right attendants present.

The resilience indicators in our example are rather straightforward, namely flood impact and flood duration. For each urban system, in the inception phase of the urban resilience planning framework, appropriate resilience indicators must be defined. The choice of indicators will depend on the hazard, type of system, available information and focus. The indicators should provide insight into the effect of measures on the impacts of floods, including the impacts of beyond-design floods as well as recovery capacity. The indicators elaborated in our examples are a subset of the indicators that may be considered in assessing the resilience of cities.

In practice, it's not feasible to study all resilience dimensions in detail. Therefore we promote a phased approach: starting from a rather coarse comprehensive analysis to identify the dimensions and elements which are most relevant for the city's resilience and then a more detailed approach where needed. In the rather broad approach interaction with actors is crucial. Approaches which structure discussions amongst actors from various organizations and disciplines are needed next to the more common detailed mono-disciplinary risk analyses.

\section{Conclusion}

We conclude that the adoption of resilience in existing city planning frameworks is a prerequisite for implementation of measures to enhance resilience. Practical tools and approaches which help decision makers to obtain and structure information and to communicate with non-flood risk experts may provide valuable contributions to this process. Resilience is a broad concept that requires a comprehensive systems approach, which may be difficult to achieve with common flood risk analysis methods and tools. Tools which engage the relevant actors, such as CIrcle and storyline method do have added value when building urban resilience to floods. These enable the gathering of tacit knowledge from actors, support discussion and contribute to the development of a mutual vision. They also help to translate technical information on possible flood events into meaningful information for actors and enable inclusive development of strategies and views on complex and interdependent problems. The methods and tools can support data sharing between organizations and build support for the implementation of risk reduction measures. The tools can be used in combination 
with traditional risk analysis methods to support decision making at different stages of resilient urban planning. The tools help to link flood risk information to flood resilience thinking.

\section{References}

[1] Roberts, E., Andrei, S., Huq, S. and Flint, L. (2015) Resilience Synergies in the Post-2015 Development Agenda. Nature Climate Change, 5, 1024-1025. https://doi.org/10.1038/nclimate2776

[2] UNISDR (United Nations International Strategy for Disaster Reduction) (2015) Sendai Framework for Disaster Risk Reduction 2015-2030. http://www.unisdr.org/files/43291_sendaiframeworkfordrren.pdf

[3] United Nations (2016) New Urban Agenda. Implementation of the Outcomes of the United Nations Conferences on Human Settlements and on Housing and Sustainable Urban Development (Habitat III) and Strengthening of the United Nations Human Settlements Programme (UN-Habitat), United Nations General Assembly, New York.

[4] United Nations (2015) Transforming Our World: The 2030 Agenda for Sustainable Development. United Nations General Assembly, New York.

[5] ARUP (2014) City Resilience Framework: ARUP \& the Rockefeller Foundation. http://publications.arup.com/publications/\%20c/\%20city_resilience_framework

[6] Folke, C. (2006) Resilience: The Emergence of a Perspective for Social-Ecological Systems Analyses. Global Environmental Change, 16, 253-267.

https://doi.org/10.1016/j.gloenvcha.2006.04.002

[7] Da Silva, J., Kernaghan, S. and Luque, A. (2012) A Systems Approach to Meeting the Challenges of Urban Climate Change. International Journal of Urban Sustainable Development, 4, 125-145. https://doi.org/10.1080/19463138.2012.718279

[8] Béné, C., Cannon, T., Gupte, J., Mehta, L. and Tanner, T. (2014) Exploring the Potential and Limits of the Resilience Agenda in Rapidly Urbanising Contexts. Evidence Report 63, Institute of Development Studies, Brighton.

[9] Schipper, L.E. and Langston, L. (2015) A Comparative Overview of Resilience Measurement Frameworks. Working Paper 422, Overseas Development Institute, London, UK.

[10] De Bruijn, M., Mens, J., Buurman, J., Dahm, R. and Klijn, F. (2017) Resilience in Practice: Five Principles to Enable Societies to Cope with Extreme Weather Events. Journal of Environmental Science and Policy, 70, 21-30. https://doi.org/10.1016/j.envsci.2017.02.001

[11] UNISDR (2012) How to Make Cities More Resilient. A Handbook for Local Government Leaders, a Contribution to the Global Campaign 2010-2015, Making Cities Resilient-My City Is Getting Ready! UNISDR, GFDRR, United Nations, Geneva.

[12] ARUP (2015) City Resilience Index: ARUP \& the Rockfeller Foundation. http://www.arup.com/city_resilience_index

[13] Abha, K.J., Miner, T.W. and Stanton-Geddes, Z. (2013) Building Urban Resilience: Principles, Tools and Practice. Directions in Development, World Bank, Washington, DC.

[14] Pirani, R. and Tolkoff, L. (2014) Lessons from Sandy. Federal Policies to Build Climate-Resiilent Coastal Regions. Policy Focus Report, Lincoln Institute of Land Policy, Cambridge, USA. 
[15] Jonkman, S.N., van Gelder, P.H.A.J.M. and Vrijling, J.K. (2003) An Overview of Quantitative Risk Measures for Loss of Life and Economic Damage. Journal of Hazardous Materials, 99, 1-30. https://doi.org/10.1016/S0304-3894(02)00283-2

[16] Kind, J.M. (2014) Economically Efficient Flood Protection Standards for the Netherlands. Journal of Flood Risk Management, 7, 103-117. https://doi.org/10.1111/jfr3.12026

[17] Merz, B., Elmer, F. and Thieken, A.H. (2009) Significance of "High Probability/Low Damage" versus "Low Probability/High Damage" Flood Events. Natural Hazards and Earth System Sciences, 9, 10331-1046. https://doi.org/10.5194/nhess-9-1033-2009

[18] Kind, J., Botzen, W. and Aerts, J. (2017) Accounting for Risk Aversion, Income Distribution and Social Welfare in Cost-Benefit Analysis for Flood Risk Management. WIREs Climate Change, 8, e446.

[19] Johnson, C., Penning-Rowsell, E. and Parker, D. (2007) Natural and Imposed Injustices: The Challenges in Implementing "Fair" Flood Risk Management Policy in England. The Geographical Journal, 173, 374-390. https://doi.org/10.1111/j.1475-4959.2007.00256.x

[20] Davoudi, S. (2012) Resilience: A Bridging Concept or a Dead End? Planning Theory \& Practice, 13, 299-307. https://doi.org/10.1080/14649357.2012.677124

[21] Biggs, R., et al. (2012) Toward Principles for Enhancing the Resilience of Ecosystem Services. Annual Review of Environment and Resources, 37, 421-448.

[22] Shaw, K. (2012) "Reframing" Resilience: Challenges for Planning Theory and Practice. Planning Theory \& Practice, 13, 308-312. https://doi.org/10.1080/14649357.2012.677124

[23] Wardekker, J.A., de Jong, A., Knoop, J.M. and van der Sluijs, J.P. (2010) Operationalising a Resilience Approach to Adapting an Urban Delta to Uncertain Climate Changes. Technological Forecasting and Social Change, 77, 987-998. https://doi.org/10.1016/j.techfore.2009.11.005

[24] Carpenter, S., Walker, B., Anderies, M.J. and Abel, N. (2001) From Metaphor to Measurement: Resilience of What to What? Ecosystems, 4, 765-781. https://doi.org/10.1007/s10021-001-0045-9

[25] De Bruijn, K.M., Diermanse, F.L.M. and Beckers, J.V.L. (2014) An Advanced Method for Flood Risk Analysis in River Deltas, Applied to Societal Flood Fatality Risk in the Netherlands. Natural Hazards and Earth System Sciences, 14, 2767-2781. https://doi.org/10.5194/nhess-14-2767-2014

[26] De Bruijn, K.M. (2005) Resilience and Flood Risk Management: A Systems Approach Applied to Lowland Rivers. Delft University of Technology, Delft, NL.

[27] Weblink. http://www.100resilientcities.org/cities/chennai/

[28] Restemeijer, B., Woltjer, J. and Van den Brink, M. (2015) A Strategy-Based Framework for Assessing the Flood Resilience of Cities-A Hamburg Case Study. Planning Theory and Practice, 16, 45-62. https://doi.org/10.1080/14649357.2014.1000950

[29] International Risk Governance Council (2005) White Paper on Risk Governance: Towards an Integrative Approach. Geneva.

[30] Weichselgartner, J. and Kelman, I. (2015) Geographies of Resilience: Challenges and Opportunities of a Descriptive Concept. Progress in Human Geography, 39, 249-267. http://phg.sagepub.com/content/39/3/249.full.pdf+html https://doi.org/10.1177/0309132513518834 
[31] Basco-Carrera, L., Warren, A., Van Beek, E., Jonoski, A. and Giardino, A. (2017) Collaborative Modelling or Participatory Modelling? A Framework for Water Resources Management. Environmental Modelling \& Software, 91, 95-110. https://doi.org/10.1016/j.envsoft.2017.01.014

[32] Dürrenberger, G. (1997) Focus Groups in Integrated Assessment: A Manual for a Participatory Tool. ZIT-Center for Interdisciplinary Studies in Technology, Darmstadt University of Technology, Darmstadt.

[33] Linstone, H. and Turoff, M. (2002) The Delphi Method: Techniques and Applications. http://is.njit.edu/pubs/delphibook/

[34] De Bruijn, K.M., Lips, N., Gersonius, B. and Middelkoop, H. (2016) The Storyline Approach: A New Way to Analyze and Improve Flood Event Management. Natural Hazards, 81, 99-121. https://doi.org/10.1007/s11069-015-2074-2

[35] Hounjet, M.W.A., Kieftenburg, A. and Altamirano, M. (2015) Learning from Flood Events on Critical Infrastructure: Relations and Consequences for Life and Environment (Circle). ICE Coastal Management 2015, 7-9 September 2015, Amsterdam, 407-413. https://www.icevirtuallibrary.com/doi/full/10.1680/cm.61149.407

[36] Burzel, A., Hounjet, M., Becker, B., Di Pietro, A., Pollino, M., Rosato, V. and Tofani, A. (2014) Towards a Decision Support System for Consequence Analysis of Flooding on Critical Infrastructure. 11 th International Conference on Hydroinformatics, 17-21 August 2014, New York. https://academicworks.cuny.edu/cc_conf_hic/99

[37] De Bruijn, K.M., Cumiskey, L., Ní Dhubhda, R., Hounjet, M. and Hynes, W. (2016) Flood Vulnerability of Critical Infrastructure in Cork, Ireland. E3S Web of Conferences, 7, Article No. 07005. https://doi.org/10.1051/e3sconf/20160707005

[38] Hynes, W. and Ní Dhubhda, R. (2016) Irish Case Study. Report of the EU Project: INTACT: On the Impact of Extreme Weather on Critical Infrastructure, Deliverable D5.3, Project Co-Funded by the European Commission under the 7th Frame-Work Programme.

[39] Halcrow (2014) Lee Catchment Flood Risk Assessment and Management Study. Hydraulics Report, Halcrow Group Ireland Limited, Dublin. 